\title{
Severe tooth loss in older adults as a key indicator of compromised dietary quality
}

\author{
Margaret R Savoca ${ }^{1, *}$, Thomas A Arcury ${ }^{2}$, Xiaoyan Leng ${ }^{2}$, Haiying Chen ${ }^{2}$, Ronny A \\ Bell ${ }^{2}$, Andrea M Anderson ${ }^{2}$, Teresa Kohrman ${ }^{2}$, Rebecca J Frazier ${ }^{1}$, Gregg H Gilbert ${ }^{3}$ \\ and Sara A Quandt ${ }^{2}$ \\ 'Department of Nutrition, University of North Carolina at Greensboro, 309 Stone Building, Greensboro, \\ NC 27402, USA: ${ }^{2}$ Wake Forest University School of Medicine, Winston-Salem, NC, USA: ${ }^{3}$ School of Dentistry, \\ University of Alabama at Birmingham, Birmingham, AL, USA
}

Submitted 18 December 2008: Accepted 14 July 2009: First published online 20 August 2009

\begin{abstract}
Objective: Poor oral health influences the dietary quality of older individuals. The objective of the present study was to relate the number of teeth to adherence to the 2005 Dietary Guidelines for Americans among an ethnically diverse sample of older adults.

Design: A block cluster design was used to obtain a sample of older adults. Data were weighted to census data for ethnicity and gender. Dietary intakes were assessed using an FFQ and converted into Healthy Eating Index-2005 (HEI-2005) scores.

Setting: Two counties in North Carolina, USA, with large African-American and American Indian populations.

Subjects: Community-dwelling older adults ( $N 635$ ).

Results: Three hundred and twenty-six participants had severe tooth loss (0-10 teeth remaining), compared with 305 participants with $11+$ teeth. After controlling for socio-economic factors, those with 0-10 teeth had lower total HEI-2005 scores and consumed less Total Fruit, Meat and Beans, and Oils, and more energy from Solid Fat, Alcohol and Added Sugar, compared with those with $11+$ teeth. Less than $1 \%$ of those with $0-10$ teeth and $4 \%$ of those with $11+$ teeth met overall HEI-2005 recommendations. Those with 0-10 teeth were less likely to eat recommended amounts of Total Vegetables, Dark Green and Orange Vegetables, and energy from Solid Fat, Alcohol and Added Sugar.

Conclusions: Older adults with severe tooth loss are less likely than those with moderate to low tooth loss to meet current dietary recommendations. Nutrition interventions for older adults should take oral health status into consideration and include strategies that specifically address this as a barrier to healthful eating.
\end{abstract}

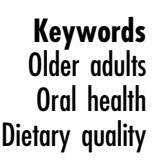

Poor oral health among older adults is among the conditions that contribute to inadequate dietary intake ${ }^{(1-7)}$. Functional limitations like not being able to chew properly or eat without pain discourage the consumption of foods that are crunchy, stringy or dry, such as vegetables, whole fruits, certain meats, or seeds and grains ${ }^{(8,9)}$. These eating difficulties compound the effects of age-related declines in taste and nutrient absorption on the nutrient status of older adults ${ }^{(10)}$. This increases the likelihood that diets will be inadequate within populations whose food choices are affected by their physical limitations, psychological decline and financial barriers ${ }^{(11-16)}$. When designing nutrition interventions or education programmes for older adults, key issues are to identify individuals with these limitations and to address the influence that compromised dental status has on their food choices.
Reduction in the number and functioning of teeth has been associated with poor diet quality among older adults. The number and location (anterior and posterior) of functional units (any opposing pair of natural or fixed prosthetic teeth) has been related to food avoidance and difficulties in chewing ${ }^{(9)}$. Several investigators have examined the role of missing posterior functional units (premolar and molar combined) in relation to dietary intake of specific nutrients or overall diet quality ${ }^{(5,17,18)}$. The fewer teeth an individual has, the more likely he or she is to have lost functioning teeth and thereby suffer compromised nutritional status.

In 1995, the US Department of Agriculture (USDA) introduced the Healthy Eating Index (HEI) to provide an approach to assess how closely diets conformed to the then-current USDA dietary recommendations ${ }^{(19)}$. 
The original HEI included a total score calculated from dietary components that represented types and amounts of foods ${ }^{(19)}$. Since its introduction, HEI scores have been used to characterize the association between impaired dental status and diet quality. Lower total HEI scores in older adults have been associated with the presence of fewer pairs of posterior teeth, denture use, poorly fitting dentures, and persistent chewing, swallowing and mouth pain $^{(5,18,20-22)}$. The HEI concept that considers overall diet quality and its component foods has been useful for considering implications of impaired dental status on the diet quality of older adults.

In 2005, new dietary guidelines were issued by the USDA (the 2005 Dietary Guidelines for Americans). In response to the new guidance, the HEI was revised ${ }^{(23)}$. This revision, now referred to as Healthy Eating Index-2005 (HEI-2005), reflects the Dietary Guidelines' increased emphasis on whole grains (particularly vegetables), certain oils, and energy from sweets, solid fats and alcohol. A second important consideration for the HEI-2005 was the use of density standards rather than absolute amounts of food (i.e. the food amounts per $4184 \mathrm{~kJ}(1000 \mathrm{kcal})$ of intake compared with the amounts per day) ${ }^{(24)}$. The use of this standard allows comparisons of nutrient intake to be independent of an individual's reported energy intake. Thus, for older adults who often have reduced energy intake $^{(25-27)}$, the HEI-2005 density standard approach provides a useful method for understanding food choices of older adults regardless of the total amounts of food ${ }^{(24)}$. To date, the HEI-2005 has not been examined among older adults, particularly those with compromised dental status.
The present paper uses data from a population-based survey that considered the oral health status and diet quality of a multi-ethnic older adult population. Its objectives are: (i) to quantify the association between the number of teeth and overall diet quality as measured by the HEI-2005; and (ii) to compare the number of teeth with the individual components of the HEI-2005.

\section{Methods}

\section{Sampling plan and recruitment}

Between January 2006 and March 2008, the Rural Nutrition and Oral Health Study conducted a cross-sectional survey of the oral health and dietary intake of an ethnically diverse sample of older adults living in rural areas of the southern USA. Participants were located using a random dwelling selection and screening procedure in which the primary sampling units (clusters) were stratified and selected with probability proportional to size. The University of Illinois Survey Research Laboratory consulted on the design and implementation of the procedure and provided final participant weights.

Clusters were stratified into four categories, based on the racial/ethnic composition of their residents, as predominantly (more than 50\%) African-American, American Indian, white or mixed (no ethnic group comprising $50 \%$ of the residents). Twenty clusters were randomly selected from each of the four types for a total of eighty clusters.

Within the eighty mapped clusters, 5545 dwelling units were identified (Fig. 1). Individuals were considered

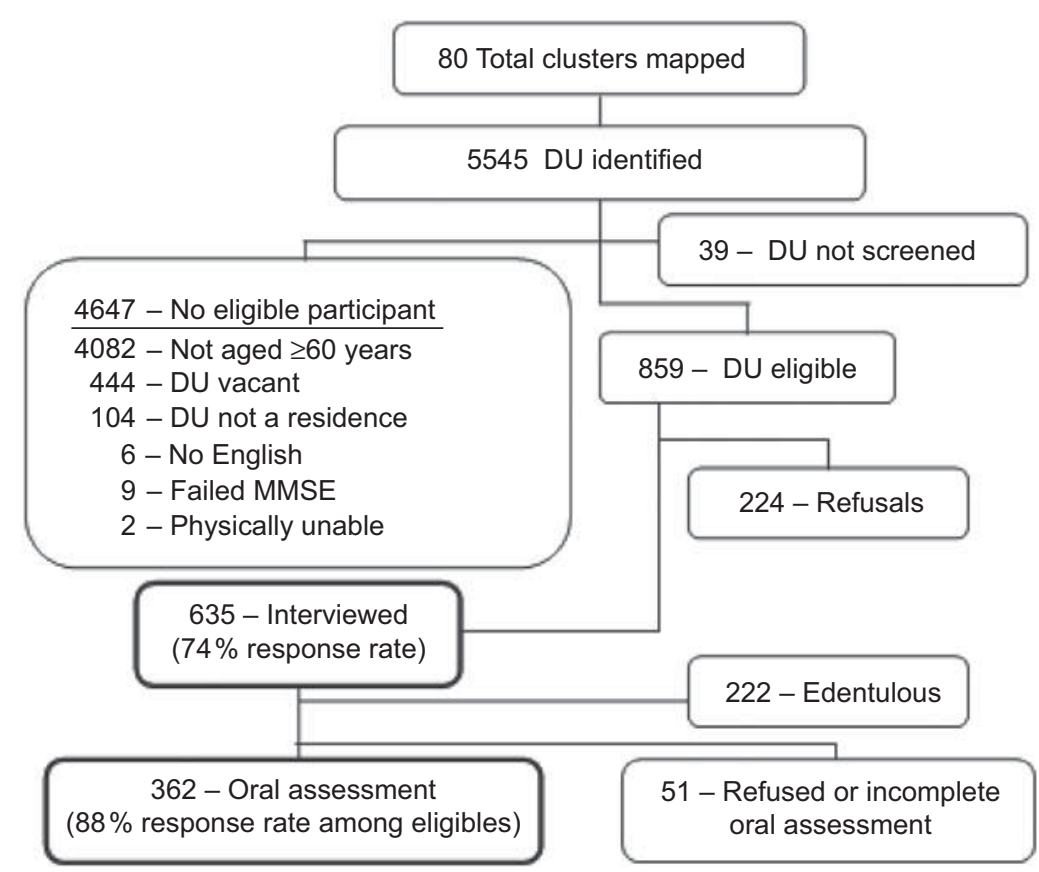

Fig. 1 Sample and recruitment for the Rural Nutrition and Oral Health Study (DU, dwelling unit; MMSE, Mini-Mental State Examination) 
eligible if they were 60 years or older, spoke English, were able to give informed consent and were physically able to complete the interview. Thirty-nine dwelling units were not screened, 4647 were screened but did not include an eligible participant and 859 included an eligible participant, yielding a screening rate of $99 \cdot 3 \%$.

The eligible residents in 635 of the 859 eligible dwelling units completed the interview and 224 refused to complete the interview, for a response rate of $73.9 \%$. The weights for each participant were based on size of the cluster from which he/she was selected and his/her probability of selection within each dwelling unit. Eightyeight per cent of those who had at least one tooth underwent an in-home oral assessment.

\section{Data collection}

All data collection procedures were approved by the university's Institutional Review Board. The data were collected in face-to-face interviews at participants' homes, lasting 1.5 to $2 \cdot 5 \mathrm{~h}$. Data collection included the 1998 version of the Block Food Frequency Questionnaire (FFQ) (Block 98.2; NutritionQuest, Berkeley, CA, USA), which assesses the usual intake of 110 foods. The use of the FFQ among this population was previously validated with a sample recruited from the same region (rural southern USA) ${ }^{(25)}$. Participants were asked about the typical frequency and portion sizes of foods they had eaten within the past year. Questions were read to participants and cue cards with response categories were used if necessary. All interviewers completed $8 \mathrm{~h}$ of training and $6 \mathrm{~h}$ of practice interviews. Ten per cent of interviews were verified by telephone. To maintain quality after initial training, one interview every month was audiorecorded for each interviewer. This tape and the accompanying completed FFQ were reviewed by research staff, who provided written feedback about recording errors or misinterpretations of the participants' responses. Dental examinations quantified tooth counts and functional occlusal contacts clinically. Two dental hygienists conducted all dental examinations. They underwent an initial $1 \mathrm{~d}$ of training and $1 \mathrm{~d}$ of calibration with a research dentist, using volunteers representative of the study population. Calibration was repeated annually. The research dentist conducted five replicate examinations with each hygienist, and performed an ongoing review of data collection forms to check for correct logic, legal values and data ranges.

\section{Demograpbic measures}

Ethnicity based upon self-report was categorized as AfricanAmerican, American Indian or white. Income was dichotomized as either above the poverty line or below the poverty line using current-year federal poverty guidelines, taking into account household size ${ }^{(28)}$. Education was categorized as (i) less than high school graduate, (ii) high school graduate or (iii) more than high school, based on the participants' highest level of education completed.

\section{Dietary assessment and Healtby Eating Index-2005 scoring}

The HEI-2005 scores were calculated from the food frequencies and completed questionnaires were scanned by NutritionQuest. In addition to standard output variables (daily micro- and macronutrient intakes and USDA food group servings of food), gram amounts and energy of each questionnaire item were provided by NutritionQuest to assist in the calculation of HEI-2005 component scores. The USDA Food Search Tool $3 \cdot 0^{(29)}$ was used to provide necessary information to calculate HEI-2005 components, such as grams per cup or ounce, amounts of fat, or added sugar in certain reference foods.

HEI-2005 contains twelve components ${ }^{(23)}$. These include cup equivalent (eq)/4184 kJ (1000 kcal) of Total Fruit, Whole Fruit, Total Vegetables, Dark Green and Orange Vegetables and Legumes (after the Meat and Bean component reaches maximum values), and Milk (including soya milk). Meat and Beans (which includes eggs, nuts and soya foods excluding drinks), Total Grains and Whole Grains are calculated in oz eq/4184 kJ $(1000 \mathrm{kcal})$. The amounts of Oils (those found in mayonnaise, margarine, salad dressing, nuts and seeds, and fish) and Sodium, measured in g/4184 kJ (1000 kcal), and the percentage of energy from Saturated Fat and Solid Fat, Alcohol and Added Sugar comprise the remaining components. The total HEI-2005 score, which ranges from 0 to 100 , is the sum of the weighted scores for each component; the contribution (weighting) of each component to the total score varies. A maximum score of 5 was assigned to component values that met or exceeded recommended intakes of Total Fruit, Whole Fruit, Total Vegetables, Dark Green and Orange Vegetables and Legumes, Total Grains and Whole Grains. A maximum score of 10 was assigned for meeting or exceeding recommended amounts of Milk, Meat and Beans, and Oils. Maximum values of 10 were also assigned when Saturated Fat and Sodium were equal to or less than recommended intake. And, finally, the recommended percentage of energy contributed by Saturated Fat and Solid Fat, Alcohol and Added Sugar was assigned a score of 20 if it was equal to or less than the recommendations. With the exception of Saturated Fat, Sodium and Saturated Fat and Solid Fat, Alcohol and Added Sugar, scores of zero were assigned to values of 0 for each of the components; and intermediate values were assigned proportionally between 0 and the maximum values.

\section{Antbropometrics}

Interviewers were trained and certified to use portable, calibrated electronic scales with a maximum weight capacity of $200 \mathrm{~kg}$ (Tanita BWB-800A; Tanita Corp., Arlington Heights, IL, USA) and portable stadiometers (Seca 214 Road Rod; Seca Corp., Hanover, MD, USA) to weigh and measure height. Participants wore light clothing when measured and measures were taken twice 
and then averaged. BMI was calculated as $\mathrm{kg} / \mathrm{m}^{2}$. Participants were classified as obese if their BMI was $\geq 30 \mathrm{~kg} / \mathrm{m}^{2}$.

\section{Oral bealth measures}

Self-reported oral health was assessed by asking participants to rate the condition of their mouth and teeth, including prosthetic teeth and dentures, as excellent, very good, good, fair or poor.

Number of remaining natural teeth was a four-level categorical variable: 0 teeth, 1-10 teeth, 11-20 teeth and 21 or more teeth. Self-reported number of teeth was used to categorize those reporting 0 teeth or those dentate participants who refused the oral exam; otherwise, dentate participants were categorized based upon the clinical examination. The Pearson correlation between the selfreported and examination values for number of teeth was 0.92 for those who agreed to the oral assessment.

The number and location (anterior or posterior) of functional units was based on a count of functional contacts between two natural teeth, a natural tooth and a fixed prosthesis, or between two fixed prostheses. Data on functional contacts were available only for the 362 oral assessment participants and those reporting zero teeth.

\section{Statistical analysis}

All data analyses incorporated the multistage cluster sampling design. The Rao-Scott $\chi^{2}$ test was used to quantify associations between gender and ethnicity, income, education, dental insurance, self-rated dental health and obesity. This test is a design-adjusted version of the Pearson $\chi^{2}$ test. For continuous variables such as age, comparisons were made through regression analysis. Linear regression models were used to test for the unadjusted effects of age, ethnicity, gender, poverty status, education, dental insurance and BMI on total HEI score. Further analyses of the effects of two number of teeth categories (0-10 teeth and $11+$ teeth) on total HEI score and its components were performed using a linear regression model after adjusting for covariates (age, gender, ethnicity, education, poverty and dental insurance). In addition, percentages meeting the requirements were calculated for $0-10$ teeth and $11+$ teeth categories. Odds ratios were calculated after adjusting covariates mentioned above using logistic regression. The distributions of total HEI score and its components were checked using histograms and the majority of these measures were bell-shaped, with exceptions that Total Fruit, Whole Fruit, Dark Green and Orange Vegetables, and Milk were right-skewed. However, no transformations were made to the latter variables since the study sample was relatively large and asymptotically the distributions approached normality. All analyses were performed using the SAS statistical software package version 9·1 (SAS Institute, Cary, NC, USA) and the significance level was set at $0 \cdot 05$.

\section{Results}

The sample comprised 344 women $(54 \cdot 1 \%)$ of whom 40.4\% were white, $35.5 \%$ American Indian and $24.2 \%$ African-American (Table 1). Among men ( $N 291$ ), 56.7\% were white, $25 \cdot 3 \%$ American Indian and 18.1\% AfricanAmerican. Women were less likely to be married (33.5\% v. $62 \cdot 1 \%, P<0 \cdot 001)$ and more likely to have income below the poverty line $(39 \cdot 7 \% v \cdot 23 \cdot 2 \%, P=0 \cdot 001)$. More than half of the participants $(55 \cdot 7 \%)$ had less than a high school education. Fifty-five per cent of participants reported having excellent, very good or good oral health, and $45 \%$ reported fair or poor oral health. Ten per cent had private dental insurance. Women were more likely to be categorized as obese as defined as BMI $\geq 30 \mathrm{~kg} / \mathrm{m}^{2}$ (44.0\% v. 30.9\%, $P=0 \cdot 03$ ).

Mean (se) daily energy intake and macronutrient composition among men were 10615 (464) kJ (2537 (111) $\mathrm{kcal})$ and $39.8(0.56) \%$ from fat, $12.9(0.30) \%$ from protein and $48.0(0 \cdot 7) \%$ from carbohydrates. Women consumed 9088 (289) kJ (2172 (69) kcal) each day, with $39 \cdot 1(0.47) \%$ from fat, $12 \cdot 8(0 \cdot 17) \%$ from protein and $50 \cdot 0(0 \cdot 60) \%$ from carbohydrates.

Participants aged 60-65 years had lower total HEI-2005 scores (mean (sE)) compared with those 75 years and older (58.68 (1.26) v. $62.97(1 \cdot 08), P=0 \cdot 02$; Table 2). Women had higher total HEI-2005 scores than men $(63 \cdot 18$ (1.01) $v .59 \cdot 19(0 \cdot 72), P=0 \cdot 0008)$. Higher total HEI-2005 scores were associated with being above the poverty level $(62.76(0.87)$ v. $58.38(1.03), P=0.0004)$ and having more than a high school education $(66 \cdot 18(1 \cdot 06))$ compared with those with only high school $(62 \cdot 22(1 \cdot 20)$, $P=0 \cdot 009)$ and less than a high school education (59.26 $(0 \cdot 76), P<0 \cdot 0001)$. Total HEI-2005 score was not associated with ethnicity, having dental insurance or BMI.

Participants with 1-10 teeth had few teeth (median $=5$ teeth), a median number of zero anterior or posterior functional units, and $11 \cdot 2 \%$ had at least one or more functional units (Table 3 ). The overall dental status of this category is very similar to individuals without any teeth. In contrast, participants with 11-20 teeth had a median number of 16 teeth with $97.5 \%$ having one or more functional units. Participants in the $21+$ category had a median of 25 teeth with $100 \%$ having one or more functional units. Those with 11-20 teeth had fewer functional units in both anterior and posterior locations. Based on the similarities between the zero and 1-10 categories and the 11-20 and 21+ categories, we evaluated diet quality with two categories, severe tooth loss (0-10 teeth; $N 326)$ and moderate to low tooth loss (11+ teeth, $N 309)$.

After adjusting for gender, ethnicity, age, poverty status and dental insurance, participants with $11+$ teeth had a higher total HEI-2005 score (mean (SE): $64 \cdot 89(0 \cdot 04))$ than those with $0-10$ teeth $(59 \cdot 39(0 \cdot 87), P<0 \cdot 0001$; Table 4$)$. Those with 0-10 teeth compared with those with $11+$ teeth 
Table 1 Demographic and health characteristics of participants: ethnically diverse community-dwelling older adults in the Rural Nutrition and Oral Health Study, southern USA, January 2006-March 2008

\begin{tabular}{|c|c|c|c|c|c|c|}
\hline & \multicolumn{2}{|c|}{ Total $(N 635)^{*}$} & \multicolumn{2}{|c|}{ Men ( $N 291)$} & \multicolumn{2}{|c|}{ Women (N 344) } \\
\hline & $N$ & $\%$ & $N$ & $\%$ & $N$ & $\%$ \\
\hline \multicolumn{7}{|l|}{ Age (years) } \\
\hline$\geq 60$ and $<65$ & 155 & $24 \cdot 4$ & 72 & 24.9 & 82 & $23 \cdot 9$ \\
\hline$\geq 65$ and $<70$ & 129 & $20 \cdot 3$ & 63 & $21 \cdot 6$ & 66 & $19 \cdot 2$ \\
\hline$\geq 70$ and $<75$ & 126 & $19 \cdot 8$ & 62 & $21 \cdot 4$ & 64 & $18 \cdot 5$ \\
\hline$\geq 75$ & 226 & $35 \cdot 5$ & 94 & $32 \cdot 1$ & 132 & $38 \cdot 4$ \\
\hline \multicolumn{7}{|l|}{ Ethnicity } \\
\hline African-American & 136 & $21 \cdot 4$ & 53 & $18 \cdot 1$ & 83 & $24 \cdot 2$ \\
\hline American Indian & 195 & $30 \cdot 7$ & 73 & $25 \cdot 3$ & 122 & $35 \cdot 5$ \\
\hline White & 304 & $47 \cdot 8$ & 165 & $56 \cdot 7$ & 139 & $40 \cdot 4$ \\
\hline Married & 296 & $46 \cdot 6$ & 181 & $62 \cdot 1$ & 115 & $33 \cdot 5$ \\
\hline Income (below poverty level) & 204 & $36 \cdot 4$ & 68 & $23 \cdot 2$ & 136 & $39 \cdot 7$ \\
\hline \multicolumn{7}{|l|}{ Education } \\
\hline Less than high school & 354 & $55 \cdot 7$ & 155 & $53 \cdot 1$ & 199 & $57 \cdot 9$ \\
\hline High school & 156 & $24 \cdot 5$ & 74 & $25 \cdot 5$ & 82 & $23 \cdot 8$ \\
\hline More than high school & 126 & $19 \cdot 8$ & 62 & $21 \cdot 4$ & 63 & $18 \cdot 4$ \\
\hline Dental insurance & 64 & $10 \cdot 1$ & 32 & $11 \cdot 0$ & 32 & $9 \cdot 3$ \\
\hline \multicolumn{7}{|l|}{ Self-rated dental health } \\
\hline Excellent & 63 & $10 \cdot 0$ & 26 & $9 \cdot 0$ & 37 & $10 \cdot 8$ \\
\hline Very good & 87 & $13 \cdot 8$ & 40 & $13 \cdot 8$ & 47 & $13 \cdot 9$ \\
\hline Good & 197 & $31 \cdot 2$ & 97 & $33 \cdot 2$ & 100 & $29 \cdot 4$ \\
\hline Fair & 170 & $26 \cdot 9$ & 79 & $27 \cdot 0$ & 91 & $26 \cdot 9$ \\
\hline Poor & 114 & $18 \cdot 1$ & 50 & $17 \cdot 0$ & 65 & $19 \cdot 0$ \\
\hline \multicolumn{7}{|l|}{ BMI $\left(\mathrm{kg} / \mathrm{m}^{2}\right)$} \\
\hline$\geq 30$ & 233 & $37 \cdot 9$ & 88 & $30 \cdot 9$ & 145 & $44 \cdot 0$ \\
\hline$\geq 25$ and $<30$ & 218 & $35 \cdot 5$ & 114 & $40 \cdot 1$ & 104 & $31 \cdot 5$ \\
\hline$<25$ & 163 & $26 \cdot 6$ & 82 & $29 \cdot 0$ & 81 & $24 \cdot 5$ \\
\hline
\end{tabular}

${ }^{*} N=$ weighted sample size.

Table 2 Bivariate relationships between the total HEl-2005 score and descriptive and oral health characteristics: ethnically diverse community-dwelling older adults $(N 635)^{*}$ in the Rural Nutrition and Oral Health Study, southern USA, January 2006-March 2008

\begin{tabular}{|c|c|c|c|}
\hline & \multicolumn{2}{|c|}{ Total HEI-2005 score } & \multirow[b]{2}{*}{$P$} \\
\hline & Mean & SE & \\
\hline \multicolumn{4}{|l|}{ Age (years) } \\
\hline $60-65$ & $58 \cdot 68$ & $1 \cdot 26$ & 0.02 \\
\hline $65-70$ & $61 \cdot 24$ & 0.93 & $0 \cdot 15$ \\
\hline $70-75$ & $61 \cdot 84$ & $1 \cdot 23$ & 0.26 \\
\hline$\geq 75$ & $62 \cdot 97$ & 1.08 & ref \\
\hline \multicolumn{4}{|l|}{ Ethnicity } \\
\hline African-American & $64 \cdot 27$ & $0 \cdot 89$ & 0.09 \\
\hline American Indian & $58 \cdot 88$ & 0.84 & 0.06 \\
\hline White & $61 \cdot 63$ & $1 \cdot 20$ & ref \\
\hline \multicolumn{4}{|l|}{ Sex } \\
\hline Female & $63 \cdot 18$ & 1.01 & 0.0008 \\
\hline Male & $59 \cdot 19$ & 0.72 & ref \\
\hline \multicolumn{4}{|l|}{ Income } \\
\hline Below poverty level & $58 \cdot 38$ & 1.03 & 0.0004 \\
\hline Above poverty level & $62 \cdot 76$ & 0.87 & ref \\
\hline \multicolumn{4}{|l|}{ Education } \\
\hline Less than high school & $59 \cdot 26$ & 0.76 & $<0.0001$ \\
\hline High school & $62 \cdot 22$ & $1 \cdot 20$ & 0.009 \\
\hline More than high school & $66 \cdot 18$ & 1.06 & ref \\
\hline \multicolumn{4}{|l|}{ Dental insurance } \\
\hline Yes & $64 \cdot 71$ & $2 \cdot 28$ & $0 \cdot 14$ \\
\hline No & $61 \cdot 0$ & 0.78 & ref \\
\hline \multicolumn{4}{|l|}{ BMI $\left(\mathrm{kg} / \mathrm{m}^{2}\right)$} \\
\hline$\geq 30$ & $62 \cdot 12$ & 0.94 & $0 \cdot 1440$ \\
\hline$\geq 25$ and $<30$ & $62 \cdot 04$ & 1.08 & 0.0668 \\
\hline$<25$ & $59 \cdot 57$ & $1 \cdot 38$ & ref \\
\hline
\end{tabular}

HEI-2005, Healthy Eating Index-2005; ref, reference value.

${ }^{*} N=$ weighted sample size. consumed less Total Fruit $(0.53(0.03) v .0 .62(0 \cdot 04)$, $P=0 \cdot 015)$, Meat and Beans $(2 \cdot 19(0 \cdot 08) v .2 \cdot 43(0 \cdot 08)$, $P=0 \cdot 01)$, and Oils $(4 \cdot 81(0 \cdot 52) v \cdot 6 \cdot 10(0 \cdot 38), P=0 \cdot 011)$. Those with $0-10$ teeth had higher intake of energy from Saturated Fat and Solid Fat, Alcohol and Added Sugar (29.31 (0.67) v. 26.38 (0.56), $P=0.0001)$ compared with those with $11+$ teeth. In addition, two trends were found. When compared with participants having with $11+$ teeth, those with $0-10$ teeth consumed fewer Total Vegetables $(0.77(0.06) v \cdot 0 \cdot 88(0 \cdot 04), P=0 \cdot 08)$ and Dark Green and Orange Vegetables and Legumes $(0 \cdot 40(0 \cdot 04) \quad v .0 \cdot 47$ $(0 \cdot 03), P=0 \cdot 08)$.

While few participants met the overall recommendation for total HEI-2005 score, less than $1 \%$ of those with $0-10$ teeth met the recommendation as compared with $3.5 \%$ of those with $11+$ teeth $(\mathrm{OR}=0 \cdot 092,95 \%$ CI $0 \cdot 02,0 \cdot 50)$. Those with $0-10$ teeth were also less likely to meet recommendations than those with $11+$ teeth for Total Vegetables (14.7\% v. 24.2\%; OR $=0 \cdot 54,95 \%$ CI 0.30, 0.98), Dark Green and Orange Vegetables and Legumes $(27 \cdot 1 \% v$. $43.6 \%$; OR $=0.48,95 \%$ CI $0.33,0.70)$ and energy from Saturated Fat and Solid Fat, Alcohol and Added Sugar $(59 \cdot 1 \% v \cdot 73 \cdot 6 \%$; OR $=0.52,95 \%$ CI $0 \cdot 35,0 \cdot 77)$.

For six of the twelve HEI food components, there were no significant differences between the number of teeth categories for either mean intake or percentage meeting recommended values. Whole Fruit and Total and Whole Grains requirements were met by approximately 20-35\% 
Table 3 Number of teeth, anterior functional units and posterior functional units by number of teeth category: ethnically diverse communitydwelling older adults in the Rural Nutrition and Oral Health Study, southern USA, January 2006-March 2008

\begin{tabular}{|c|c|c|c|c|}
\hline \multirow[b]{2}{*}{ Oral health characteristic } & \multicolumn{4}{|c|}{ Number of teeth } \\
\hline & $\begin{array}{c}0 \\
(N 221)^{*}\end{array}$ & $\begin{array}{c}1-10 \\
(N 105)\end{array}$ & $\begin{array}{c}11-20 \\
(N 131)\end{array}$ & $\begin{array}{c}21+ \\
(N 178)\end{array}$ \\
\hline Number of teeth (median) & 0 & 5 & 16 & 25 \\
\hline Number of anterior functional units (median) & 0 & 0 & 4 & 6 \\
\hline Number of posterior functional units (median) & 0 & 0 & 2 & 6 \\
\hline Participants with at least one functional unit (\%) & 0 & $11 \cdot 2$ & $97 \cdot 5$ & 100 \\
\hline
\end{tabular}

${ }^{*} N=$ weighted sample size.

Table 4 Total HEl-2005 score, estimated intake of HEl components and the percentage of participants meeting HEl-2005 recommendations for each category: ethnically diverse community-dwelling older adults in the Rural Nutrition and Oral Health Study, southern USA, January 2006-March 2008

\begin{tabular}{|c|c|c|c|c|c|c|c|c|c|}
\hline \multirow[b]{3}{*}{$\mathrm{HEI}-2005$ category and recommendations } & \multicolumn{5}{|c|}{ HEI values } & \multicolumn{4}{|c|}{ Percentage meeting $\mathrm{HEI}$ recommendations } \\
\hline & \multicolumn{2}{|c|}{$0-10$ teeth$^{*}$} & \multicolumn{2}{|c|}{$11+$ teeth$^{*}$} & \multirow[b]{2}{*}{$P$} & \multirow{2}{*}{$\frac{0-10 \text { teeth }}{\%}$} & \multirow{2}{*}{$\frac{11+\text { teeth }}{\%}$} & \multirow[b]{2}{*}{ OR } & \multirow[b]{2}{*}{$95 \% \mathrm{Cl}$} \\
\hline & Meant & SE & Mean & SE & & & & & \\
\hline $\begin{array}{l}\text { Total Score } \\
\quad \geq 80\end{array}$ & $59 \cdot 39$ & $0 \cdot 87$ & $64 \cdot 89$ & 0.04 & $<0.0001$ & $0 \cdot 3$ & $3 \cdot 5$ & 0.092 & $0.02,0.50$ \\
\hline $\begin{array}{l}\text { Total Fruit } \\
\quad \geq 0 \cdot 8 \text { cup eq } / 4184 \mathrm{~kJ} \ddagger\end{array}$ & 0.53 & $0 \cdot 03$ & $0 \cdot 62$ & $0 \cdot 04$ & $0 \cdot 015$ & $15 \cdot 5$ & $20 \cdot 9$ & $0 \cdot 69$ & $0.44,1.09$ \\
\hline $\begin{array}{l}\text { Whole Fruit } \\
\quad \geq 0 \cdot 4 \text { cup eq } / 4184 \mathrm{~kJ}\end{array}$ & 0.35 & 0.03 & 0.39 & 0.03 & $0 \cdot 11$ & $28 \cdot 5$ & $37 \cdot 8$ & $0 \cdot 66$ & $0 \cdot 38,1 \cdot 12$ \\
\hline $\begin{array}{l}\text { Total Vegetables } \\
\geq 1 \cdot 1 \text { cup eq } / 4184 \mathrm{~kJ}\end{array}$ & $0 \cdot 77$ & 0.06 & $0 \cdot 88$ & 0.04 & 0.08 & $14 \cdot 7$ & $24 \cdot 2$ & 0.54 & $0.30,0.98$ \\
\hline $\begin{array}{l}\text { Dark Green and Orange Vegetables } \\
\text { and Legumes } \\
\geq 0.4 \text { cup eq } / 4184 \mathrm{~kJ}\end{array}$ & $0 \cdot 40$ & 0.04 & 0.47 & 0.03 & 0.08 & $27 \cdot 1$ & $43 \cdot 6$ & $0 \cdot 48$ & $0.33,0.70$ \\
\hline $\begin{array}{l}\text { Total Grains } \\
\geq 3.0 \mathrm{oz} / 4184 \mathrm{~kJ}\end{array}$ & $2 \cdot 56$ & $0 \cdot 10$ & $2 \cdot 61$ & 0.09 & 0.67 & $28 \cdot 8$ & $27 \cdot 0$ & $1 \cdot 09$ & $0 \cdot 66,1 \cdot 82$ \\
\hline $\begin{array}{l}\text { Whole Grains } \\
\qquad 1.5 \mathrm{oz} / 4184 \mathrm{~kJ}\end{array}$ & 0.96 & 0.08 & $1 \cdot 02$ & 0.08 & $0 \cdot 30$ & $15 \cdot 4$ & $19 \cdot 6$ & $0 \cdot 75$ & $0.45,1 \cdot 24$ \\
\hline $\begin{array}{l}\text { Milk } \\
\qquad 1.3 \text { cup eq/4184 } \mathrm{kJ}\end{array}$ & 0.46 & 0.04 & 0.47 & 0.04 & 0.77 & $3 \cdot 8$ & $3 \cdot 6$ & $1 \cdot 05$ & $0 \cdot 38,2 \cdot 88$ \\
\hline $\begin{array}{l}\text { Meat and Beans } \\
\geq 2.5 \mathrm{oz} \text { eq } / 4184 \mathrm{~kJ}\end{array}$ & $2 \cdot 19$ & 0.08 & $2 \cdot 43$ & 0.08 & 0.01 & $30 \cdot 6$ & $40 \cdot 8$ & 0.64 & $0 \cdot 37,1 \cdot 12$ \\
\hline $\begin{array}{l}\text { Oils } \\
\qquad \geq 12 \mathrm{~g} \mathrm{eq} / 4184 \mathrm{~kJ}\end{array}$ & $4 \cdot 81$ & 0.52 & $6 \cdot 10$ & 0.38 & $0 \cdot 011$ & $2 \cdot 7$ & $5 \cdot 1$ & 0.52 & $0 \cdot 20,1 \cdot 35$ \\
\hline $\begin{array}{l}\text { Saturated Fat } \\
\leq 7 \% \text { of energy }\end{array}$ & $11 \cdot 17$ & $0 \cdot 21$ & $10 \cdot 93$ & 0.22 & 0.42 & $1 \cdot 2$ & $1 \cdot 6$ & $0 \cdot 75$ & $0 \cdot 32,1 \cdot 78$ \\
\hline $\begin{array}{l}\text { Sodium } \\
\leq 700 \mathrm{mg} / 4184 \mathrm{~kJ}\end{array}$ & $1321 \cdot 2$ & $26 \cdot 1$ & $1324 \cdot 4$ & $24 \cdot 1$ & $0 \cdot 85$ & 0.00 & 0.00 & - & - \\
\hline $\begin{array}{l}\text { Energy from Solid Fat, Alcohol } \\
\text { and Added Sugar } \\
\leq 20 \% \text { of energy }\end{array}$ & $29 \cdot 31$ & $0 \cdot 67$ & $26 \cdot 38$ & 0.56 & 0.0001 & $59 \cdot 1$ & $73 \cdot 6$ & 0.52 & $0.35,0.77$ \\
\hline
\end{tabular}

HEl-2005, Healthy Eating Index-2005.

*Weighted samples for tooth loss categories: 0-10 teeth, $n 326 ; 11+$ teeth, $n 309$.

tAdjusted for gender, ethnicity, age, poverty status and dental insurance.

$\ddagger 4184 \mathrm{~kJ}=1000 \mathrm{kcal}$.

of all participants. Fewer than $5 \%$ of participants met Milk and Saturated Fat recommendations. All participants exceeded recommended Sodium intake.

\section{Discussion}

In this ethnically diverse sample of older adults, we found that approximately half of the sample had severe tooth loss ( $0-10$ teeth remaining) and that these individuals had lower adherence to the USDA 2005 Dietary Guidelines ${ }^{(30)}$ compared with those with $11+$ teeth. Our findings that those with $0-10$ teeth had few functional units in any location are consistent with reports of older adults with chewing problems having fewer teeth, fewer total functional units and fewer posterior functional units compared with those without chewing complaints $^{(9)}$. Independent of the effects of age, sex, poverty status, dental insurance status and education, having $0-10$ teeth was associated with a 5-point lower diet quality score compared with those with $11+$ teeth. This difference was comparable to or greater than differences found in total 
HEI scores associated with age, sex, poverty status and education.

The participants with fewer teeth had either low intake or low rates of adherence to recommendations for six of the twelve food groups emphasized by the current USDA guidance $^{(30)}$. Differences in estimated intake per $4184 \mathrm{~kJ}$ $(1000 \mathrm{kcal})$ of Total Fruit, Whole Fruit, Total Vegetables, Meat and Beans, and Oils between those with 0-10 teeth and those with $11+$ teeth represented about $10 \%$ of the recommended amounts of these food categories. The differences in Dark Green and Orange Vegetables and Legumes and energy from Saturated Fat and Solid Fat, Alcohol and Added Sugar represented 15\% of current recommendations.

The six components related to the number of teeth represent $55 \%$ of the 100 points that comprise the total HEI-2005 score. The remaining $45 \%$ of this score included Whole Fruit, Total and Whole Grains, Milk, Saturated Fat and Sodium components. Regardless of the number of teeth, at least $96 \%$ of participants failed to consume enough milk products and exceeded guidelines for saturated fat and sodium. The majority (70-80\%) of all participants failed to consume adequate amounts of Whole Fruit and Total and Whole Grains.

A report using the original HEI index found that total HEI and HEI fruit component scores were higher for those with five to eight posterior functional units than for those with fewer functional units, those without teeth and those with a full denture ${ }^{(5)}$. However, another report found few associations between the number of posterior functional units and the original HEI total and component scores $^{(18)}$. Among older adults assessed for their consumption of certain foods, nutrient and dietary intake, and nutritional status, those with 1-10 teeth had significantly more difficulty eating apples and certain kinds of bread and vegetables ${ }^{(17)}$. Those with fewer teeth had lower intakes of fibre, total carbohydrates, energy, protein, fat and certain micronutrients, and comparable differences were found for those with fewer posterior functional units ${ }^{(17)}$. It appears that both number of teeth and number of posterior functional units have similar relationships with dietary intake and nutritional status.

Two-thirds of participants in the present research with severe tooth loss (0-10 teeth) were edentulous (having no teeth) and, among the remaining third, only $11 \%$ had any functional units. The USDA has found that edentulous persons have less varied and poorer-quality diets containing fewer servings of fruits and vegetables, compared with the population as whole ${ }^{(31)}$. Among older adults (age 70-79 years), edentulous persons consumed less energy from protein, dietary fibre, and fruits and fruit juices, as well as more sweets, desserts, fats and oils ${ }^{(32)}$. Within a large sample of male health professionals, those who were edentulous consumed fewer vegetables and less dietary fibre, apples, pears and carrots than those with 25 or more teeth ${ }^{(2)}$. A report from the National
Health and Nutrition Examination Survey (1988-94) found that those who had only 1-10 teeth consumed fewer carrots and salads and had lower serum levels of $\beta$-carotene, folate and vitamin $C^{(33)}$. This is consistent with the present findings where those with severe tooth loss ate fewer fruits and vegetables and consumed less meat and more energy from solid fat and added sugar.

The effect of impaired dental status on efforts to improve the diets of older adults has important implications for public health nutrition, particularly as it relates to fruit and vegetable consumption. Younger and older adults who were more socially isolated, had poor selfreported health, were obese and had fewer pairs of posterior teeth were at the highest risk of consuming low amounts of fruits and vegetables ${ }^{(6)}$. Lack of dental insurance leading to tooth loss was identified by older low-income women as a barrier to increased fruit and vegetable consumption( ${ }^{(34)}$. Perceived chewing ability explained $4 \%$ of the variance in fruit and vegetable consumption among middle-aged to older adults ${ }^{(35)}$.

Fruit and vegetable interventions for older adults have focused on psychosocial variables, such as locus of control or self-efficacy ${ }^{(36)}$. Others were designed to increase knowledge and skills related to healthful recipes and shopping ${ }^{(37,38)}$. Including recipes modified for those with impaired chewing ability may be a useful strategy for older adults ${ }^{(39)}$. When barriers to fruit and vegetable intake were measured at baseline, 'chewing or dental problems' were reported by $19 \%$ of participants exceeded only by 'cost' (24\%) and 'difficulties with digestion' $(20 \%)^{(38)}$. The perception of 'chewing or dental problems' remained unchanged at the end of the 4-month intervention ${ }^{(38)}$. The large number of participants with 0-10 teeth in the present study suggests that dietary interventions targeted at older adults should consider categorizing participants based on the simple measure of the number of teeth to assess the severity of their tooth loss. Intervention strategies to address the needs of those with severe tooth loss should be considered.

Our study has several strengths. It is a populationbased sample that includes older adults from three ethnic groups and considers oral health status along with diet quality. It utilizes the HEI-2005 scoring system, which represents the most recent USDA recommendation, and as such provides an opportunity to examine the components based on a density standard. Although many reports have considered the effectiveness of posterior functional units in relation to diet quality, we have demonstrated that categorizing individuals based on severe tooth loss $v$. moderate to low losses can provide useful information about diet quality of older adults.

The study has limitations. First, the HEI-2005 as developed by USDA relies on a single $24 \mathrm{~h}$ recall to assess individual food choices ${ }^{(40)}$. We adapted the HEI-2005 scoring system to the FFQ output using an approach to categorizing foods similar to HEI-2005 guidance. The use 
of the FFQ is considered to be a valid approach for comparison of groups, providing a better description of usual diet than a single $24 \mathrm{~h}$ recall, and is suitable for the present investigation ${ }^{(41)}$. Prior research validated the FFQ using the average of six $24 \mathrm{~h}$ recalls for comparison. The FFQ provided results that allowed the comparison of dietary intake across participants in the present study population ${ }^{(25)}$. Second, under-reporting of energy intake by rural older adults can potentially introduce bias into comparisons between groups ${ }^{(27,42)}$. These previous reports have found that rural older adults are failing to report both healthful and unhealthful foods. The HEI-2005 density standard approach can minimize the impact of under-reporting by allowing scoring to be independent of individual's reported energy intake ${ }^{(23)}$. Third, our study was a cross-sectional investigation, and thus a causal relationship between oral health status and food choices cannot be established.

In summary, older adults with severe tooth loss have low adherence to the USDA 2005 Dietary Guidelines for Americans. Although overall older adults were not meeting recommendations, our findings showed that in food groups emphasized in the 2005 USDA guidance, older adults with severe tooth loss had a greater disadvantage compared with those with more teeth. The oral health status of older adults should become a key consideration in efforts to understand and improve the diet quality of older adults.

\section{Acknowledgements}

Support for this research was provided by the National Institute for Dental and Craniofacial Research, grant R01 DE017092. No authors have any conflicts of interest. M.R.S. developed the analytic strategy, interpreted the data, wrote the initial manuscript and oversaw the preparation of the final manuscript; T.A.A. contributed to study design and interpreted the data; X.L. conducted the statistical analysis and interpreted the data; H.C. conducted the statistical analysis and interpreted the data; R.A.B. contributed to study design and interpreted the data; A.M.A. provided statistical analyses; T.K. acquired the subjects and participated in manuscript preparation; R.J.F. contributed to the literature review, interpreted the data and participated in manuscript preparation; G.H.G. interpreted the data; and S.A.Q. oversaw study design, interpreted the data and participated in writing of the manuscript. All authors participated in writing of the final manuscript.

\section{References}

1. Hung HC, Colditz G \& Joshipura KJ (2005) The association between tooth loss and the self-reported intake of selected CVD-related nutrients and foods among US women. Community Dent Oral Epidemiol 33, 167-173.

2. Joshipura KJ, Willett WC \& Douglass CW (1996) The impact of edentulousness on food and nutrient intake. J Am Dent Assoc 127, 459-467.
3. Krall E, Hayes C \& Garcia R (1998) How dentition status and masticatory function affect nutrient intake. $J$ Am Dent Assoc 129, 1261-1269.

4. Marshall TA, Warren JJ, Hand JS, Xie XJ \& Stumbo PJ (2002) Oral health, nutrient intake and dietary quality in the very old. J Am Dent Assoc 133, 1369-1379.

5. Sahyoun NR, Lin CL \& Krall E (2003) Nutritional status of the older adult is associated with dentition status. J Am Diet Assoc 103, 61-66.

6. Sahyoun NR, Zhang XL \& Serdula MK (2005) Barriers to the consumption of fruits and vegetables among older adults. J Nutr Elder 24, 5-21.

7. Walls AW \& Steele JG (2004) The relationship between oral health and nutrition in older people. Mech Ageing Dev 125, 853-857.

8. Gilbert GH, Duncan RP, Heft MW, Dolan TA \& Vogel WB (1997) Oral disadvantage among dentate adults. Community Dent Oral Epidemiol 25, 301-313.

9. Hildebrandt GH, Dominguez BL, Schork MA \& Loesche WJ (1997) Functional units, chewing, swallowing, and food avoidance among the elderly. J Prosthet Dent 77, 588-595.

10. Chernoff R (editor) (2006) Geriatric Nutrition: The Health Professional's Handbook, 3rd ed. Boston, MA: Jones and Bartlett.

11. Clarkston WK, Pantano MM, Morley JE, Horowitz M, Littlefield JM \& Burton FR (1997) Evidence for the anorexia of aging: gastrointestinal transit and hunger in healthy elderly vs. young adults. Am J Physiol 272, R243-R248.

12. de Castro JM (2002) Age-related changes in the social, psychological, and temporal influences on food intake in free-living, healthy, adult humans. J Gerontol $\mathbf{5 7 A}$, 368-377.

13. Dean M, Grunert KG, Raats MM, Nielsen NA \& Lumbers M; Food in Later Life Team (2008) The impact of personal resources and their goal relevance on satisfaction with food-related life among the elderly. Appetite 50, 308-315.

14. Garry PJ, Hunt WC, Koehler KM, VanderJagt DJ \& Vellas BJ (1992) Longitudinal study of dietary intakes and plasma lipids in healthy elderly men and women. Am J Clin Nutr 55, 682-688.

15. Hays JC, Keller HH \& Ostbye T (2005) The effects of nutrition-related factors on four-year mortality among a biracial sample of community-dwelling elders in the North Carolina piedmont. J Nutr Elder 25, 41-67.

16. Sturm K, MacIntosh CG, Parker BA, Wishart J, Horowitz M \& Chapman IM (2003) Appetite, food intake, and plasma concentrations of cholecystokinin, ghrelin, and other gastrointestinal hormones in undernourished older women and well-nourished young and older women. J Clin Endocrinol Metab 88, 3747-3755.

17. Sheiham A \& Steele J (2001) Does the condition of the mouth and teeth affect the ability to eat certain foods, nutrient and dietary intake and nutritional status amongst older people? Public Health Nutr 4, 797-803.

18. Shinkai RS, Hatch JP, Sakai S, Mobley CC, Saunders MJ \& Rugh JD (2001) Oral function and diet quality in a community-based sample. J Dent Res 80, 1625-1630.

19. Kennedy ET, Ohls J, Carlson S \& Fleming K (1995) The Healthy Eating Index: design and applications. J Am Diet Assoc 95, 1103-1108.

20. Bailey RL, Ledikwe JH, Smiciklas-Wright H, Mitchell DC \& Jensen GL (2004) Persistent oral health problems associated with comorbidity and impaired diet quality in older adults. J Am Diet Assoc 104, 1273-1276.

21. Sahyoun NR \& Krall E (2003) Low dietary quality among older adults with self-perceived ill-fitting dentures. $J \mathrm{Am}$ Diet Assoc 103, 1494-1499.

22. Shinkai RS, Hatch JP, Rugh JD, Sakai S, Mobley CC \& Saunders MJ (2002) Dietary intake in edentulous subjects 
with good and poor quality complete dentures. J Prosthet Dent 87, 490-498.

23. Guenther PM, Reedy J, Krebs-Smith SM, Reeve BB \& Basiotis PP (2007) Development and Evaluation of the Healthy Eating Index-2005: Technical Report. http:// www.cnpp.usda.gov/HealthyEatingIndex.htm (accessed June 2008).

24. Ritchie CS, Joshipura K, Hung HC \& Douglass CW (2002) Nutrition as a mediator in the relation between oral and systemic disease: associations between specific measures of adult oral health and nutrition outcomes. Crit Rev Oral Biol Med 13, 291-300.

25. Quandt SA, Vitolins MZ, Smith SL, Tooze JA, Bell RA, Davis CC, DeVellis RF \& Arcury TA (2007) Comparative validation of standard, picture-sort and meal-based food-frequency questionnaires adapted for an elderly population of low socio-economic status. Public Health Nutr 10, 524-532.

26. Sharkey JR (2008) Diet and health outcomes in vulnerable populations. Ann N Y Acad Sci 1136, 210-217.

27. Tooze JA, Vitolins MZ, Smith SL, Arcury TA, Davis CC, Bell RA, DeVellis RF \& Quandt SA (2007) High levels of low energy reporting on 24-hour recalls and three questionnaires in an elderly low-socioeconomic status population. J Nutr 137, 1286-1293.

28. US Department of Health and Human Services (2006) Annual Update on the HHS Poverty Guidelines. Fed Reg 71, 3848-3849.

29. US Department of Agriculture (2008) What's in the Foods You Eat Search Tool, 3.0. http://www.ars.usda.gov/ foodsearach (accessed June 2008).

30. Fogli-Cawley JJ, Dwyer JT, Saltzman E, McCullough ML, Troy LM \& Jacques PF (2006) The 2005 Dietary Guidelines for Americans Adherence Index: development and application. J Nutr 136, 2908-2915.

31. Ervin RB (2008) Healthy Eating Index scores among adults, 60 years of age and over, by sociodemographic and health characteristics: United States, 1999-2002. Adv Data issue 395, 1-16.

32. Lee JS, Weyant RJ, Corby P, Kritchevsky SB, Harris TB, Rooks R, Rubin SM \& Newman AB (2004) Edentulism and nutritional status in a biracial sample of well-functioning, community-dwelling elderly: the health, aging, and body composition study. Am J Clin Nutr 79, 295-302.
33. Nowjack-Raymer RE \& Sheiham A (2003) Association of edentulism and diet and nutrition in US adults. J Dent Res 82, 123-126.

34. Dye CJ \& Cason KL (2005) Perceptions of older, lowincome women about increasing intake of fruits and vegetables. J Nutr Elder 25, 21-41.

35. Bradbury J, Thomason JM, Jepson NJ, Walls AW, Mulvaney CE, Allen PF \& Moynihan PJ (2008) Perceived chewing ability and intake of fruit and vegetables. J Dent Res $\mathbf{8 7}$, $720-725$.

36. Greene GW, Fey-Yensan N, Padula C, Rossi SR, Rossi JS \& Clark PG (2008) Change in fruit and vegetable intake over 24 months in older adults: results of the SENIOR project intervention. Gerontologist 48, 378-387.

37. Bernstein A, Nelson ME, Tucker KL, Layne J, Johnson E, Nuernberger A, Castaneda C, Judge JO, Buchner D \& Singh MF (2002) A home-based nutrition intervention to increase consumption of fruits, vegetables, and calcium-rich foods in community dwelling elders. J Am Diet Assoc 102, 1421-1427.

38. Hendrix SJ, Fischer JG, Reddy RD, Lommel TS, Speer EM, Stephens H, Park S \& Johnson MA (2008) Fruit and vegetable intake and knowledge increased following a community-based intervention in older adults in Georgia senior centers. J Nutr Elder 27, 155-178.

39. Bradbury J, Thomason JM, Jepson NJ, Walls AW, Allen PF \& Moynihan PJ (2006) Nutrition counseling increases fruit and vegetable intake in the edentulous. J Dent Res $\mathbf{8 5}$, 463-468.

40. Freedman LS, Guenther PM, Krebs-Smith SM \& Kott PS (2008) A population's mean Healthy Eating Index-2005 scores are best estimated by the score of the population ratio when one 24-hour recall is available. J Nutr $\mathbf{1 3 8}$, $1725-1729$.

41. Subar AF, Thompson FE, Kipnis V, Midthune D, Hurwitz P, McNutt S, McIntosh A \& Rosenfeld S (2001) Comparative validation of the Block, Willett, and National Cancer Institute food frequency questionnaires: the Eating at America's Table Study. Am J Epidemiol 154, 1089-1099.

42. Bailey RL, Mitchell DC, Miller C \& Smiciklas-Wright H (2007) Assessing the effect of underreporting energy intake on dietary patterns and weight status. J Am Diet Assoc 107, 64-71. 